\title{
The Prevalence of Attention-Deficit/ Hyperactivity Disorder among Primary School Students in an Iranian Rural Region
}

\author{
Hamid Alizadeh1, Esmaeel Armion², Frederick L. Coolidge ${ }^{3 *}$, Zaena D. Flores ${ }^{3}$, \\ Courtney E. Sutton ${ }^{3}$ \\ ${ }^{1}$ Allameh Tabataba'i University, Tehran, Iran \\ ${ }^{2}$ Exceptional Children Organization, Tehran, Iran \\ ${ }^{3}$ University of Colorado, Colorado Springs, USA \\ Email: * fcoolidg@uccs.edu
}

Received 27 January 2015; accepted 11 February 2015; published 12 February 2015

Copyright (C) 2015 by authors and Scientific Research Publishing Inc.

This work is licensed under the Creative Commons Attribution International License (CC BY). http://creativecommons.org/licenses/by/4.0/

(c) (i) Open Access

\section{Abstract}

This study investigated the prevalence of attention-deficit/hyperactivity disorder (ADHD) in a rural population in Birjand, south east Iran. The total population of elementary students in this region was 3408. A random sample method selected 1381 children ( 727 boys, and 654 girls; mean of age $=8.2$ years, $S D=1.5$ years). Conners Rating Scales and Diagnostic and the Statistical Manual for Mental Disorders (DSM-IV-TR) were used for screening and diagnosis of ADHD. Ninety-nine students $(7.2 \%$ of the students) were identified as ADHD $(10.3 \%$ of the boys and $3.7 \%$ of the girls). The combined ADHD subtype was the most prevalent (44\%), hyperactive-impulsive subtype was second $(38 \%)$, and inattentive was third $(17 \%)$. This subtype pattern was the same for boys, however, hyperactive-impulsive subtype more prevalent in girls (63\%). It seems that ADHD appears to be a common problem among primary school children in the rural Iran, and findings are similar but higher than world-wide ADHD prevalence estimates $(5.3 \%)$. The present prevalence rate for ADHD is closer to world-wide study estimates that are based on DSM-IV and International Classification of Diseases (ICD-10) criteria.

\section{Keywords}

ADHD, ADHD Prevalence, Rural Region, Iran

\footnotetext{
${ }^{*}$ Corresponding author.
} 


\section{Introduction}

Attention-deficit/hyperactivity disorder (ADHD) is a world-wide phenomenon, but interestingly, the prevalence estimates for ADHD in children range vary widely from as low as $1 \%$ to as high as $20 \%$ (Polanczyk, de Lima, Horta, Biederman, \& Rohde, 2007). In their review of 102 studies of 171,756 children world-wide, Polanczyk et al. found a pooled prevalence of ADHD of 5.3\%. From the results of their meta-regression model, they concluded that geographic location played a limited role in prevalence determinance, while impairment criteria, diagnostic criteria, and the sources of information (parents, teachers, mental health professionals, etc.) played predominant roles. There are far fewer prevalence studies of types of ADHD, however, Biederman et al. (2002) found that the combined type of ADHD was the most prevalent for both boys and girls, but girls were more than twice as likely to be diagnosed as inattentive type than boys. It does appear clear that epidemiological studies of ADHD are helpful in understanding issues related to its frequency, distributions, and determinants. Accurate estimates for the prevalence of ADHD in children are also critical to providing the mental health services needed.

In the present study, the purposes were two-fold: The first was to estimate ADHD prevalence in a largely rural Iranian population. One justification for this purpose is that there have been a number of studies of ADHD in children in Iran, however, they were estimates performed in larger cities. For example, ADHD prevalence in large cities ranges from 4\% in Zahedan (Jamshidi-Chenari, 2005), 4.5\% in Tehran (Khoshabi \& Pour-Etemad (2004), 9\% in Gonabad (Tavakoli, Boulhari, Mehryar, \& Dejkaam, 1997), 11\% in Kashan (Akasheh, 2003), to 12\% in Mashhad (Hebrani, Abdolahian, Behdani, Vosoogh, \& Janbakht, 2007). A second purpose was to determine whether the prevalence of ADHD varied widely when there was adherence to standard criteria, that is, employment of diagnostic criteria from the Diagnostic and Statistical Manual of Mental Disorders (DSM-IV-TR; American Psychiatric Association, 2000) and International Classification of Disease (ICD-10; World Health Organization, 2007), specific definitions of behavioral impairment, and use of standardized measures. It was hypothesized that ADHD prevalence estimates in rural Iranian populations of children would be similar to worldwide prevalence estimates when the aforementioned criteria were used.

\section{Method}

\subsection{Sample and Participant Selection}

In this population-based prevalence research, participants were recruited from rural areas near Birjand, and the center of South Khorasan province in eastern Iran (an area near the eastern border of Iran with Afghanistan). The total number of elementary students in these areas was 3408. Using a cluster random method, 1381 students (40.5\% of the population) ages 6 to 11 years old were selected ( 727 boys, 654 girls). The data were collected during the six-month period October 2006 to March 2007 to ensure that each class teacher had enough time to become familiar with their students and complete the Conner's Teacher Rating Scales, which assesses ADHD symptoms. A total of 129 students (out of 1381) were identified by the teachers through the Conner's as potentially having ADHD. Subsequently, the parents of this sample completed a checklist about their children which listed the 18 criteria for ADHD from DSM-IV-TR (see the Measures section for details). Through this method, 99 children were identified as having ADHD.

\subsection{Measures}

Two questionnaires were used to collect the data. A Persian translated version of the Conners' Teacher Rating Scales was used initially to screen for ADHD symptoms. The Persian version was reviewed by a bilingual consultant and then translated by a bilingual psychologist. It has been established that teacher- and parent-rated scales can reliably provide necessary information about children in school settings (e.g., Goyette, Connoers, \& Ulrich, 1978; Miller, Koplewicz, \& Idein, 1997). Conners' scales have been widely used in many different cultures and languages, and it is acknowledged to be reliable and valid in non-western settings (e.g., Daradkeh, 1993). The translated Conners' ADHD measure's internal scale reliability has previously been reported to be $\alpha$ $=.93$ in Iranian children (Sohrabi, 2000).

The criteria for ADHD diagnoses and its subtypes were established by adherence to the DSM-IV-TR and ICD-10 criteria. There were 18 ADHD symptoms corresponding to 18 criteria in DSM-IV-TR (9 inattention items, 6 hyperactive items, and 3 impulsive items). Each item was scored on a scale of 0 (no), and 1 (yes) by the children's parents if the children's behaviors were persistent across the six-month observation period (as re- 
quired by $D S M-I V-T R$ criterion). According to the criteria for the ADHD diagnostic types in DSM-IV-TR, a score of 6 or greater on the 9 inattention items was required for a diagnosis of Predominantly Inattentive Type, a score of 6 or greater on the 9 hyperactive/impulsive items was required for a diagnosis of Predominantly Hyperactive-Impulsive Type, and a score of 6 or greater on the inattention items along with a score of 6 or greater on the hyperactive/impulsive were required for a diagnosis of Combined Type.

\subsection{Procedure}

First, the purpose of the research was explained to school authorities, and the required prerequisite permission was obtained to contact the students' parents. All of the school authorities, teachers, and parents volunteered to participate in this study (i.e., verbal informed consent), and all were aware they could decline participation without penalty. No specific mention was made of pathologies, abnormalities, or diagnosis in order to prevent bias in completing the checklist. The parents of the 129 children initially identified as having ADHD by the Conner's Teacher Rating Scales were presented the ADHD DSM-IV-TR checklist and were told that the information would help the researchers gain a better understanding about the problems some students experience in school. The checklists were returned to school within one week. When the parents had queries about specific items, they were able to request consultation by phone or in person.

\section{Results}

Table 1 summarizes the prevalence rates as a function of gender, age, and ADHD type as determined by the parents according to the Conners' Ratings Scales (which is consistent with DSM-IV-TR criteria). The overall ADHD prevalence rate in this sample was determined to be 7.2\% (99/1381). For boys, this prevalence rate of ADHD was $10.3 \%(75 / 727)$. For girls, this prevalence rate of ADHD was $3.7 \%(24 / 654)$. A $\chi^{2}$ analysis $\left[\chi^{2}(1, N\right.$ $=1381)=22.86, p<.001]$ revealed that the ADHD prevalence rate for boys was significantly greater than the ADHD prevalence rate for girls, so boys were approximately 2.8 times more likely to be diagnosed with ADHD than girls.

With regard to the prevalence of types of ADHD as a function of gender, a $\chi^{2}$ analysis revealed that there was no significant difference between genders for Predominantly Inattentive Type ( $17.3 \%$ for boys, $16.7 \%$ for girls). However, girls were more than twice as likely as boys to be the Predominantly Hyperactive-Impulsive Type (62.5\% vs. $30.7 \%$ ), while boys were more than twice as likely to be the Combined Type than girls (52.0\% vs. $20.8 \%), \chi^{2}(2, \mathrm{~N}=99)=8.78, p=.012$.

A $\chi^{2}$ analysis for relationship between students' age (collapsed into 8 years old and younger, and greater than 8 years old $)$ and ADHD prevalence $\left[\chi^{2}(1, N=1381)=9.30, p=.002\right]$ revealed that the prevalence rate decreased with age (9.1\% for the younger group, $5.1 \%$ for the older group). A Pearson correlation between the six age levels and ADHD prevalence rate at each age level revealed a strong negative correlation, $\mathrm{r}(4)=-.86, p$ $=.028$. The highest ADHD prevalence rate was $10.0 \%$ for the age level 7 years, and the lowest rate was $3.7 \%$ for age level 11 years. Table 2 presents ADHD prevalence and ADHD type as a function of age.

The ADHD prevalence rate was also analyzed separately for boys and girls as a function of age level. For boys, a Pearson correlation between the six age levels and ADHD prevalence rate at each age level revealed a strong negative correlation, $\mathrm{r}(4)=-.87, p=.025$. The highest ADHD prevalence rate for boys was $14.4 \%$ for the age level 8 years, and the lowest rate was $6.2 \%$ for age level 11 years. For girls, a Pearson correlation between the six age levels and ADHD prevalence rate at each age level also revealed a strong negative correlation, $r(4)=$ $-.92, p=.01$. The highest ADHD prevalence rate for girls was $7.2 \%$ for the age level 7 years, and the lowest rate was $1.4 \%$ for age level 11 years.

Table 1. ADHD prevalence as a function of gender and ADHD type.

\begin{tabular}{|c|c|c|c|c|c|c|c|c|c|}
\hline ADHD & & Inattentive & & Hyperactive & & Combined & & & \\
\hline Gender & $\mathrm{N}$ & Percent of ADHD & $\mathrm{N}$ & Percent of ADHD & $\mathrm{N}$ & Percent of ADHD & $\mathrm{N}_{\mathrm{ADHD}}$ & $\begin{array}{c}\text { Total } \\
\text { Sample }\end{array}$ & $\begin{array}{c}\text { ADHD } \\
\text { Prevalence }\end{array}$ \\
\hline Boys & 13 & 17 & 23 & 31 & 39 & 52 & 75 & 727 & $10.3 \%$ \\
\hline Girls & 4 & 17 & 15 & 63 & 5 & 21 & 24 & 654 & $3.7 \%$ \\
\hline Total & 17 & 17 & 38 & 38 & 44 & 44 & 99 & 1381 & $7.2 \%$ \\
\hline
\end{tabular}


Table 2. ADHD prevalence as a function of age and ADHD type.

\begin{tabular}{|c|c|c|c|c|c|c|c|c|c|}
\hline ADHD & & Inattentive & & Hyperactive & & Combined & & & \\
\hline $\begin{array}{c}\text { Age } \\
\text { (in years) }\end{array}$ & $\mathrm{N}$ & Percent of ADHD & $\mathrm{N}$ & Percent of ADHD & $\mathrm{N}$ & Percent of ADHD & $\mathrm{N}_{\mathrm{ADHD}}$ & $\begin{array}{l}\text { Total } \\
\text { Sample }\end{array}$ & $\begin{array}{c}\text { ADHD } \\
\text { Prevalence }\end{array}$ \\
\hline 6 & 1 & 9 & 4 & 36 & 6 & 55 & 11 & 136 & $8.1 \%$ \\
\hline 7 & 6 & 20 & 13 & 43 & 11 & 37 & 30 & 301 & $10 \%$ \\
\hline 8 & 3 & 14 & 9 & 41 & 10 & 46 & 22 & 238 & $9.2 \%$ \\
\hline 9 & 2 & 13 & 7 & 44 & 7 & 44 & 16 & 238 & $6.7 \%$ \\
\hline 10 & 2 & 20 & 2 & 20 & 6 & 60 & 10 & 200 & $5.0 \%$ \\
\hline 11 & 3 & 30 & 3 & 30 & 4 & 40 & 10 & 268 & $3.7 \%$ \\
\hline Total & 17 & 17 & 38 & 38 & 44 & 44 & 99 & 1381 & $7.2 \%$ \\
\hline
\end{tabular}

\section{Discussion}

In Iran, there have been few attempts to conduct population-based prevalence studies of ADHD, particularly in rural settings. Some epidemiological studies of ADHD, in Iran as well as in the rest of the world, have been conducted with clinic-referred samples of children (e.g., Jensen et al., 1999; Rowland, Lesesne, \& Abramowitz, 2002) which present difficulties in precisely reflecting the actual epidemiologic rates. Therefore, populationbased prevalence studies are valuable in order to enhance the knowledge about ADHD among different populations in varying regions.

In the present study, the major hypothesis was largely confirmed: The overall ADHD prevalence rate of this sample of rural Iranian children of $7.2 \%$ was similar (but higher) to a world-wide, pooled prevalence rate of ADHD of 5.3\%. This rate is mostly consistent with some other Iranian studies from various regions and large cities, ranging from about $4.5 \%$ to $12 \%$ (as noted in detail earlier). It is important to note however that none of these studies employed the present methodology of a population-based random sample, as this method would be prohibitive because the cities cited earlier in this paper range in population from about 135,000 to over 13,000,000. The ADHD prevalence rate in the present study was also similar to studies conducted in the Middle East and Far East, for example, the ADHD prevalence rate was 8.1\% in Turkey (Ersan, Dogan, Dogan, \& Sumer, 2001), 9.4\% in Qatar (Bener, Al Qahtani, \& Abdelaal, 2006), and 8.9\% in China (Leung et al. 1996).

With regard to type of ADHD, the present findings varied from some previous research conducted in the USA (Biederman et al., 2002). Biederman et al. found the combined type to be most prevalent for both boys and girls, while girls were more than twice as likely to be the Predominantly Inattentive type. In the present study, boys were more likely to be the combined type than the other two types, but they were more than 2.5 times as likely to be the combined type as girls. The present study found no differences between boys and girls with regard to the Predominantly Inattentive type.

The gender analysis in the present study was also consistent with world-wide research (e.g., Barkley, 1998; Brown et al., 2001; Goldstein \& Goldstein, 1998) as the boys' prevalence rate of ADHD (10.3\%) was significantly greater than the girls' (3.7\%), and thus, the boys ADHD rate in this rural region of Iran was almost three times greater than in girls. The present study also found that ADHD prevalence rates appeared to decrease significantly with age from about $9.1 \%$ for those under 8 years old and under $5.1 \%$ for those over 8 years old. Furthermore, the lowest prevalence rate in the present study was 3.7\% for the group of 11 year olds. This decrease in ADHD prevalence rate as a function of age did not differ significantly between boys and girls, and this finding, is consistent with previous studies (e.g., Bener et al., 2006; Simon, Czobor, Bálint, Mészáros, \& Bitter, 2009; McCarthy et al., 2009). Further analysis for each gender separately and distinguished between age levels for ADHD prevalence revealed strong negative correlations in both boys and girls. In other words, identification for ADHD prevalence was significantly lower in older boys and girls than in younger boys and girls when analyzed separately by gender at each age level.

The results of the present study may help to guide decisions about the needs of children with behavior problems with regard to treatment interventions and to efforts aimed at preventing the worsening of behavior problems over time. The results of the present study may also have some important public policy implications. Scahill and Schwab-Stone (2000) noted that "because it could have a fundamental influence on the allocation of re- 
sources for prevention and treatment, the prevalence of a disease in the population has important implications for health policy” (p. 542).

One limitation of the present study is that medical histories for the children were not obtained, as particular medical conditions and syndromes may affect behavior and are sometimes comorbid with ADHD such as anxiety, mood, or developmental disorders (e.g., Polanczyk et al., 2007). Another limitation was that individual clinical interviews and behavioral observations were not conducted with the children. Consistent with previous studies, the findings do suggest that geographic rural location may have a limited role in determining ADHD prevalence rates as the present findings are consistent with other prevalence studies in much larger cities, despite our adherence to $D S M-I V-T R$ criteria and our cluster random method. Future studies are also strongly suggested for investigations into the types of ADHD, particularly with regard to gender differences, as the present findings in this regard varied somewhat from previous research.

\section{References}

Akasheh, G. (2003). The Association between ADHD and Demographic Variable in Elementary Students in Kashan in 2001-2002. Isfahan: Research Report, Research Council, Education Department. (In Persian)

American Psychiatric Association (2000). Diagnostic and Statistical Manual of Mental Disorders (4th ed.). Washington DC: American Psychiatric Association.

Barkley, R. A. (1998). Attention-Deficit Hyperactive Disorder: A Handbook for Diagnosis and Treatment (2nd ed.). New York: Guilford Press.

Bener, A., Al Qahtani, R., \& Abdelaal, I. (2006). The Prevalence of ADHD among Primary School Children in an Arabian Society. Journal of Attention Disorders, 10, 77-82. http://dx.doi.org/10.1177/1087054705284500

Biederman, J., Mick, E., Faraone, S. V., Braaten, E., Doyle, A., \& Spencer, T. (2002). Influence of Gender on Attention Deficit Hyperactivity Disorder in Children Referred to a Psychiatric Clinic. American Journal of Psychiatry, 159, 39-42. http://dx.doi.org/10.1176/appi.ajp.159.1.36

Brown, R. T., Freeman, W. S., Perrin, J. M., Stein, M. T., Amler, R. W., Feldman, H. M., Pierce, K., \& Wolraich, M. L. (2001). Prevalence and Assessment of Attention Deficit/Hyperactivity Disorder in Primary Care Settings. Pediatrics, 107, 3. http://dx.doi.org/10.1542/peds.107.3.e43

Daradkeh, T. K. (1993). Parent-Teacher Reliability in Rating Children on the 10-Items Conners Rating Scale. Egypt Journal of Psychiatry, 16, 52-56.

Ersan, E. E., Dogan, O., Dogan, S., \& Sumer, H. (2001). The Distribution of Symptoms of Attention-Deficit/Hyperactivity Disorder and Oppositional Defiant Disorder in School Age Children in Turkey. European Child and Adolescent Psychiatry, 13, 354-361. http://dx.doi.org/10.1007/s00787-004-0410-2

Goldstein, S., \& Goldstein, M. (1998). Managing Attention Deficit Hyperactivity Disorder in Children: A Guide for Practitioners (2nd ed.). New York: Wiley.

Goyette, C. H., Conners, C. K., \& Ulrich, R. F. (1978). Normative Data on Revised Conners Parent and Teacher Rating scales. Journal of Abnormal Child Psychology, 6, 221-236. http://dx.doi.org/10.1007/BF00919127

Hebrani, P., Abdolahian, E., Behdani, F., Vosoogh, I., \& Javanbakht, A. (2007). The Prevalence of Attention Deficit Hyperactivity Disorder in Preschool-Age Children in Mashhad, North East of Iran. Archives of Iranian Medicine, 10, 147-151.

Jamshidi-Chenari, N. (2005). The Epidemiology and Demographics of ADHD in Sistan and Balouchestan Province. Unpublished Master Dissertation, Birjand: Islamic Azad University. (In Persian)

Jensen, P. S., Kettle, L., Roper, M. T., Sloan, M. T., Dulcan, M. K., Hoven, C. et al. (1999). Are Stimulants Overprescribed? Treatment of ADHD in Four US Communities. Journal of the American Academy of Child and Adolescent Psychiatry, 38, 797-804. http://dx.doi.org/10.1097/00004583-199907000-00008

Leung, P. W., Luk, S. L., Ho, T. P., Taylor, E., Mak, F. L., \& Bacon-Shore, J. (1996). The Diagnosis and Prevalence of Hyperactivity in Chinese School Boys. British Journal of Psychiatry, 168, 486-496. http://dx.doi.org/10.1192/bjp.168.4.486

McCarthy, S., Asherson, P., Coghill, D., Hollis, C., Murray, M., Potts, L., Sayal, K., de Soysa, R., Taylor, E., Williams, T., \& Wong, I. C. (2009). Attention-Deficit Hyperactivity Disorder: Treatment Discontinuation in Adolescents and Young Adults. The British Journal of Psychiatry, 194, 273-277. http://dx.doi.org/10.1192/bjp.bp.107.045245

Miller, L. S., Koplewicz, H. S., \& Idein, R. G. (1997). Teacher Ratings of Hyperactivity, Inattention and Conduct Problems in Preschoolers. Journal of Abnormal Child Psychology, 25, 13-119. http://dx.doi.org/10.1023/A:1025727428097

Polanczyk, G., de Lima, M. S., Horta, B. L., Biederman, J., \& Rohde, L. A. (2007). The Worldwide Prevalence of ADHD: A Systematic Review and Metaregression Analysis. The American Journal of Psychiatry, 164, 942-948. 
http://dx.doi.org/10.1176/ajp.2007.164.6.942

Rowland, A. S., Lesesne, C. A., \& Abramowitz, A. J. (2002). The Epidemiology of Attention-Deficit/Hyperactivity Disorder (ADHD). Mental Retardation and Developmental Disabilities, 8, 162-170. http://dx.doi.org/10.1002/mrdd.10036

Scahill, L., \& Schwab-Stone, M. (2000). Epidemiology of ADHD in School-Age Children. Child and Adolescent Psychiatric Clinics of North America, 9, 541-555.

Simon, V., Czobor, P., Bálint, S., Mészáros, A., \& Bitter, I. (2009). Prevalence and Correlates of Adult Attention-Deficit Hyperactivity Disorder: Meta-Analysis. The British Journal of Psychiatry, 194, 204-211. http://dx.doi.org/10.1192/bjp.bp.107.048827

Sohrabi, N. (2000). An Investigation on DSM-IV Reliability. Unpublished Master Dissertation, Tehran: Tehran University. (In Persian)

Szatmari, P., Offord, D. R., \& Boyle, M. H. (1989). Prevalence of Attention Deficit Disorder with Hyperactivity. Journal of Child Psychology and Psychiatry, 30, 219-230. http://dx.doi.org/10.1111/j.1469-7610.1989.tb00236.x

Tavakoli, J., Boulhari, J., Mehryar, A. H., \& Dejkaam, M. (1997). Epidemiology of Disruptive Behavioral Disorders and Attention Deficit in Elementary Students. Andisheva Raftar, 3, 40-51. (In Persian)

Taylor, E., Sandberg, S., Thorley, G., \& Gilles, S. (1991). Hyperkinetic Disorder: Prevalence, Definition, and Associations. In E. Taylor, S. Sandberg, \& G. Thorley (Eds.), The Epidemiology of Childhood Hyperactivity (Maudsley Monographs) (pp. 93-113). Oxford: Oxford University Press. 
Scientific Research Publishing (SCIRP) is one of the largest Open Access journal publishers. It is currently publishing more than 200 open access, online, peer-reviewed journals covering a wide range of academic disciplines. SCIRP serves the worldwide academic communities and contributes to the progress and application of science with its publication.

Other selected journals from SCIRP are listed as below. Submit your manuscript to us via either submit@scirp.org or Online Submission Portal.
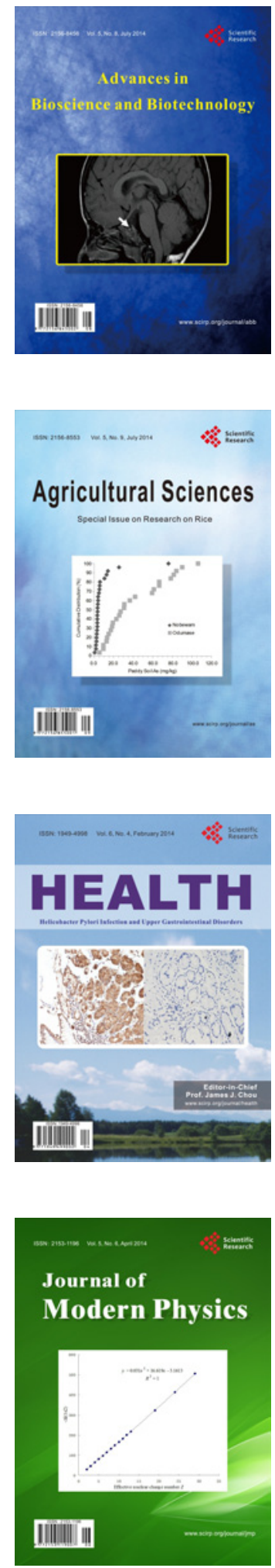
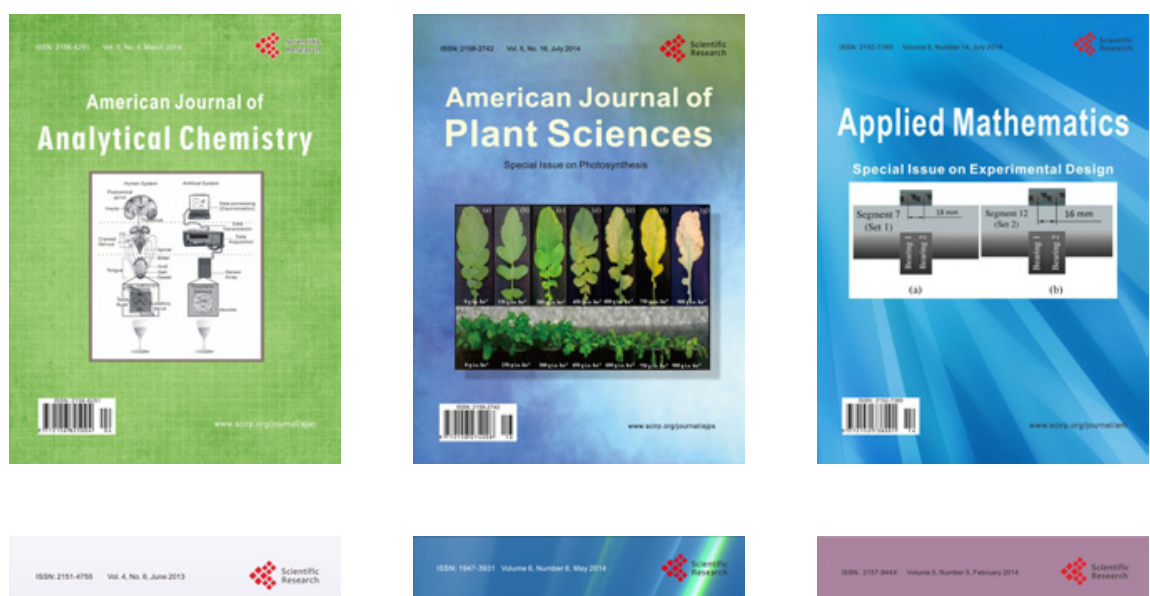

Creative Education
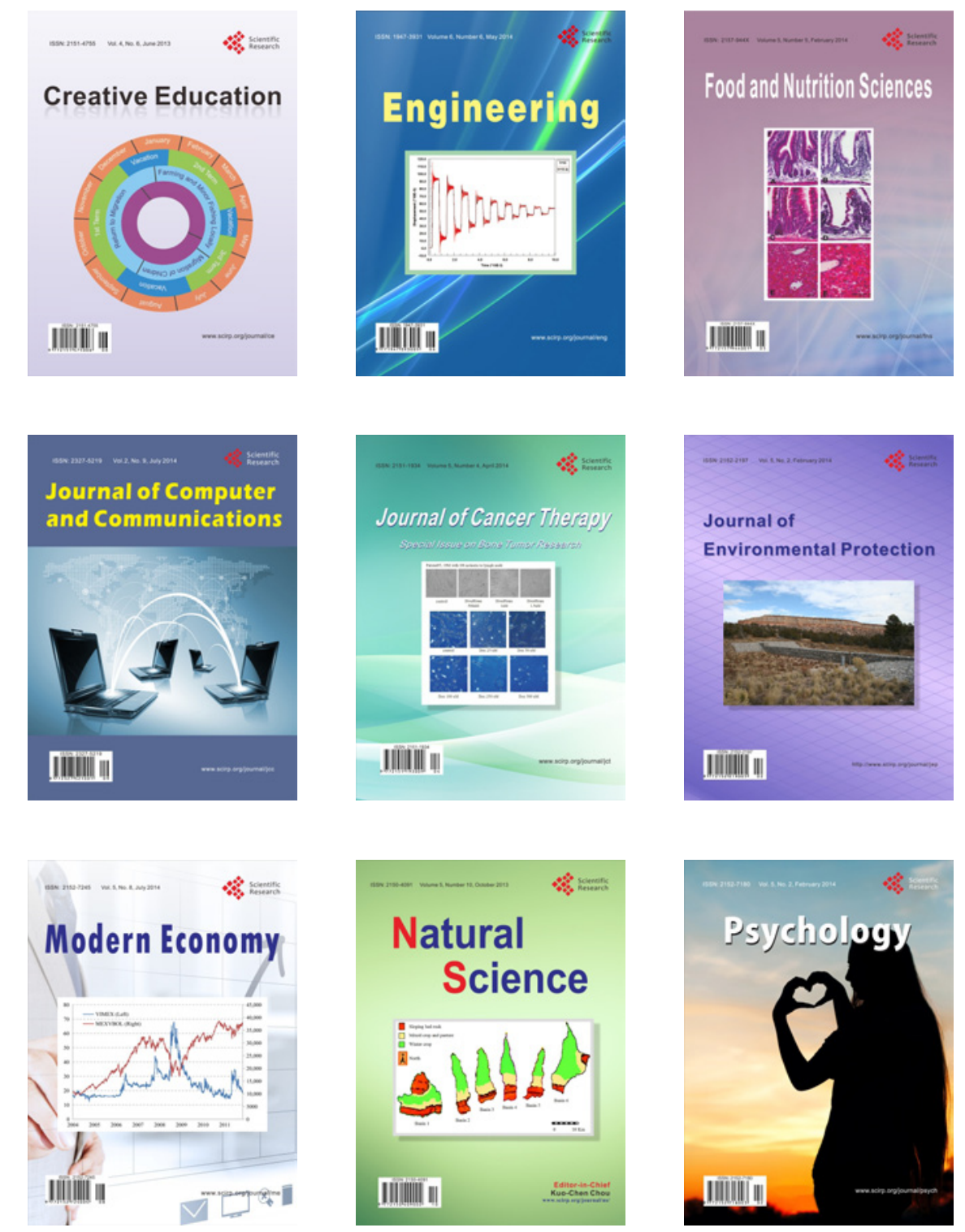